\title{
ANALYSIS OF STERNAL CURVATURE PATTERNS IN PATIENTS WITH PECTUS AND CONTROL
}

\section{ANÁLISE DOS PADRÕES DE CURVATURA ESTERNAL EM PACIENTES COM PECTUS E CONTROLES}

\author{
Davi de Podestá Haje ${ }^{1,2}$ (1), Kelsen de Oliveira Teixeira ${ }^{2}$ (i), Moacir Silva Neto ${ }^{2}$ (1), José Batista Volpon ${ }^{3}$ (1), \\ Paulo Sergio Mendlovitz ${ }^{4}$ (1), Paulo Dolabela 5 (1)
}

1. Centro Clínico Orthopectus, Brasília, DF, Brazil.

2. Department of Pediatric Orthopaedics and Physical Medicine and Rehabilitation, Hospital de Base do Distrito Federal, Secretaria de Estado da Saúde do Distrito Federal, Brasília, DF, Brazil. 3. Department of Biomechanics, Medicine and Rehabilitation of the Locomotor System, University of São Paulo, Ribeirão Preto, SP, Brazil.

4. Sabin Medicina Diagnóstica, Brasília, DF, Brazil.

5. Department of Radiology and Medical Imaging, Clínica Villas Boas, Brasília, DF, Brazil.

\section{ABSTRACT}

Objective: To analyze reformatted sagittal sternal tomography images and classify sternal body curvature types, and compare different types of pectus populations with one another and with normal individuals. Methods: In total, 50 controls and 167 pectus patients were selected for chest CT to analyze the median sagittal plane, of whom 89 had pectus carinatum (mean age, $12 \pm 10$ years) and 78 pectus excavatum (mean age, $14 \pm 10$ years). Clinical types of pectus were classified as inferior, superior, or lateral pectus carinatum, and localized or broad pectus excavatum. The following types of sternal patterns were defined: gradual vertical curve, gradual posterior curve, gradual anterior curve, proximal third curve, middle third curve, distal third curve, anterior rectilinear, vertical rectilinear, and posterior rectilinear. Statistical analyses were performed to compare the different types of pectus with one another and with the control group. Results: Patients with different thoracic deformities, but with similar sternal curvature patterns, were observed. Some types of sternal curvature were significantly more frequent in certain types of pectus $(p<0,05)$. The gradual vertical curve and anterior rectilinear types prevailed in controls $(p<0,05)$. Conclusion: Some sternal curvature patterns were more frequent than the others in certain types of pectus and the controls. Level of Evidence II, Prognostic studies - investigating the effect of a patient characteristic on the outcome of disease.

Keywords: Pectus Carinatum. Pectus Excavatum. Thorax. Tomography. Tomography, X-ray Computed.
RESUMO

Objetivo: Avaliar a reformatação sagital tomográfica do esterno por meio da análise de uma classificação do tipo de curvatura do corpo esternal nos diferentes tipos de pectus, comparando-os entre si e com indivíduos normais. Métodos: 50 controles e 167 pacientes submetidos à TC do tórax para análise da reconstrução sagital no plano mediano, sendo $89 \mathrm{com}$ pectus carinatum (idade média, $12 \pm 10$ anos) e 78 com pectus excavatum (idade média, $14 \pm 10$ years). Os tipos clínicos de pectus foram classificados em: pectus carinatum superior, inferior e lateral, e pectus excavatum amplo ou localizado. Foram definidos os seguintes tipos de padrões esternais: curvo gradativo vertical; curvo gradativo posterior; curvo gradativo anterior; curvo terço proximal; curvo terço médio; curvo terço distal; retilíneo anterior; retilíneo vertical; e retilíneo posterior. Foi realizada análise estatística entre o grupo pectus e controle, e entre diferentes tipos de pectus. Resultados: Observamos pacientes com deformidades torácicas diferentes, mas com esternos com padrão de curvatura semelhante. Alguns tipos de curvatura esternal são significativamente mais frequentes em alguns tipos de pectus $(p<0,05)$. Em controles prevaleceram os tipos curvo gradativo vertical e retilíneo anterior $(p<0,05)$. Conclusão: Alguns tipos de curvatura esternal são mais frequentes que outras em determinados tipos de pectus e controles. Nível de Evidência II, Estudos prognósticos - investigação do efeito de característica de um paciente sobre o desfecho da doença.

Descritores: Pectus Carinatum. Pectus Excavatum. Tórax. Tomografia. Tomografia Computadorizada.

Citation: Haje DP, Teixeira KO, Silva Neto M, Volpon JB, Mendlovitz PS, Dolabela P. Analysis of sternal curvature patterns in patients with pectus and control. Acta Ortop Bras. [online]. 2021;29(5):258-262. Available from URL: http://www.scielo.br/aob.

\section{INTRODUCTION}

The anterior thoracic wall has been well studied in images acquired in the coronal and axial planes. ${ }^{1,2}$ However, few authors have analyzed the sagittal plane region in cases of anterior chest deformity or pectus; thus, differentiating the types of pectus and distinguishing these patients from normal individuals may be useful.

Haje et al. ${ }^{3}$ developed radiographic indices that show the relative length of various sternal segments visualized in the profile incidence.

All authors declare no potential conflict of interest related to this article.

The study was conducted at Centro Clínico Orthopectus.

Correspondence: Davi P. Haje. SMHN, Q. 2 BI. A, sala 804, Edifício de Clínicas, Asa Norte, Brasília, DF, Brazil, 70710904. davihaje@yahoo.com.br

Article received on 09/18/2020, approved on 11/05/2020. 
From this analysis, the authors concluded that the developmental changes in the sternum, such as ossification and maturation with consequent shortening and curving of the body, seem to have a major influence on the etiology of superior pectus carinatum and a minor influence on other types of pectus. ${ }^{3}$

Through the evaluation of coronal images, some sternal anatomical variations have been described, especially those related to skeletal maturation and age. ${ }^{4}$

Interpreting tomographic sections in sagittal reformatted images of patients with pectus can be difficult. The sternal body curvature patterns in the sagittal plane may pose challenges when distinguishing patients with pectus from normal individuals. Therefore, a better knowledge of the sternal anatomy in different types of pectus in the sagittal plane is a necessary propaedeutic for radiologists, orthopedists, and thoracic surgeons, which may help them to better understand the etiopathogenesis of these deformities and improve treatment

Our study aimed to evaluate the reformatted sagittal sternal computed tomography (CT) images, analyze and classify sternal body curvature types in the sagittal plane in normal and pectus populations, and verify any predefined patterns that may exist.

\section{MATERIALS AND METHODS}

Institutional Review Board approval (42165414.5.0000.5553) was obtained. This was a retrospective analysis of medical records from 5,750 individuals with pectus treated between February 2004 and September 2014 at our Hospital.

\section{Study participants}

We selected 181 consecutive patients with pectus from this population that had undergone CT of the thorax involving the sternum and costal cartilages ( $1 \mathrm{~mm}$ slice thickness and interval). The exclusion criteria were previous resection surgery of the costal cartilage $(n=3)$, iatrogenic pectus $(n=1)$, and deformities associated with scoliosis greater than $10^{\circ}(\mathrm{n}=10)$. Finally, 67 patients with pectus and 50 control individuals were included for analyzing the sternum in the sagittal plane. The patients with pectus and the controls were subdivided for the analysis, as shown in Table 1.

Table 1. Subdivisions of the pectus and control groups.

\begin{tabular}{|c|c|c|c|c|c|}
\hline \multicolumn{5}{|c|}{$\begin{array}{c}\text { Pectus group } \\
(n=167,133 \text { men })\end{array}$} & \multirow{2}{*}{$\begin{array}{c}\text { Control group } \\
(n=50, \text { mean age }, \\
29 \quad 23 \text { years })\end{array}$} \\
\hline \multicolumn{3}{|c|}{$\begin{array}{l}\text { pectus carinatum } \\
\text { ( } n=89 \text {, mean age, } \\
1210 \text { years) }\end{array}$} & \multicolumn{2}{|c|}{$\begin{array}{c}\text { pectus excavatum } \\
(\mathrm{n}=78, \text { mean age } \\
1410 \text { years })\end{array}$} & \\
\hline $\begin{array}{c}\text { IPC } \\
(n=52)\end{array}$ & $\begin{array}{c}\text { LPC } \\
(n=24)\end{array}$ & $\begin{array}{c}\text { SPC } \\
(n=13)\end{array}$ & $\begin{array}{c}\text { LPE } \\
(n=52)\end{array}$ & $\begin{array}{c}\text { BPE } \\
(n=26)\end{array}$ & control $(n=50)$ \\
\hline
\end{tabular}

IPC: inferior pectus carinatum; LPC: lateral pectus carinatum; SPC: superior pectus carinatum; LPE: Iocalized pectus excavatum; BPE: broad pectus excavatum.

Clinical diagnosis was established by the evaluators (DPH, MSN), who classified pectus according to the predominant type as follows: inferior pectus carinatum (IPC) (Group I), lateral pectus carinatum (LPC) (Group II), superior pectus carinatum (SPC) (Group III), Iocalized pectus excavatum (LPE) (Group IV), and broad pectus excavatum (BPE) (Group V). ${ }^{5}$

Patients in the control group underwent chest CT scans $11 \mathrm{~mm}$ slice thickness and interval) for other reasons. They did not have pectus or spinal deformities, and did not report prior surgeries in the sternal region. The controls were randomly selected from the image banks of the radiology clinics involved in the study.

\section{Analysis}

The images were selected in Digital Imaging and Communications in Medicine (DICOM $®$ ) format using the OsiriX v. 5.8.2 32-Bit software (Pixmeo SARL, Bernex, Switzerland) for the image reconstruction. Images in the sagittal plane were standardized using the MIP 3D evaluation software to amplify the slices since the sternum of these patients may present substantial variations in the coronal and sagittal planes. The closest possible slice to the median plane of the sternum was analyzed.

The following types of sternal patterns were defined by the main author based on the analysis of sternal body images (Figures 1 and 2):



Figure 1. Flowchart showing the sternal curvature patterns.

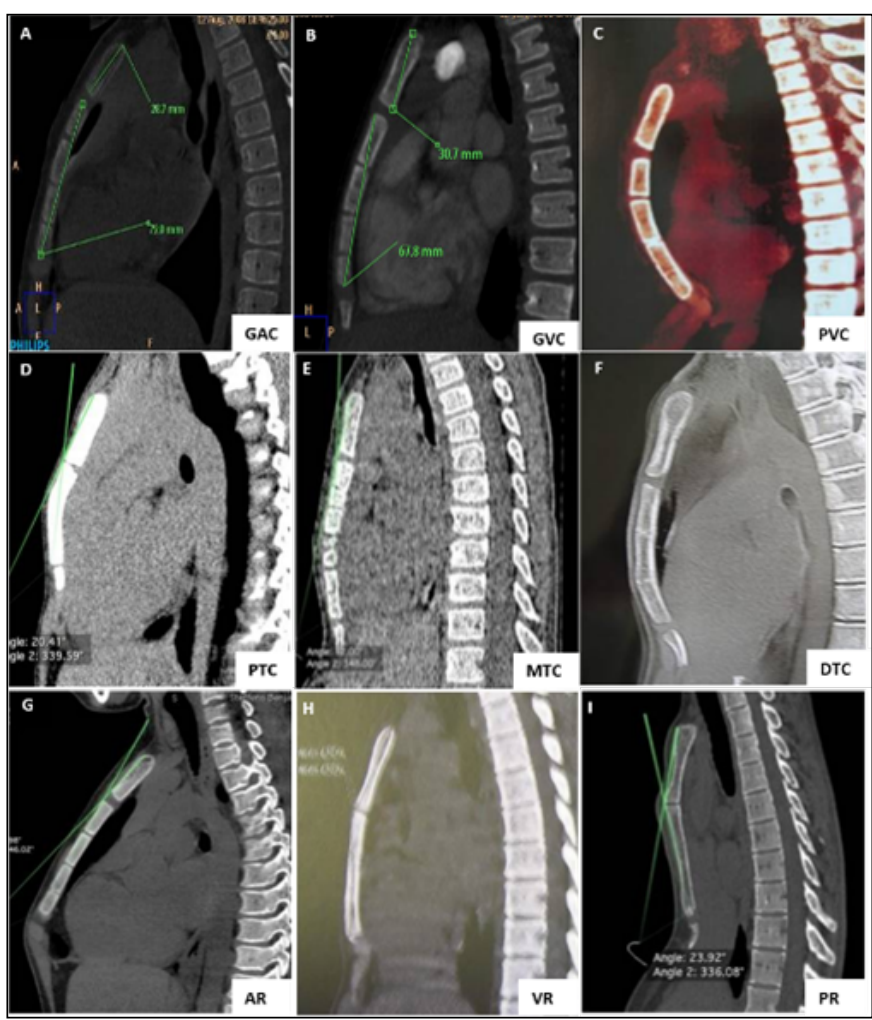

Figure 2. Illustration of sternal patterns. Sternum: gradual anterior curve (GAC); gradual vertical curve (GVC); gradual posterior curved (GPC); proximal third curve (PTC); middle third curve (MTC); distal third curve (DTC); anterior rectilinear (AR); vertical rectilinear (VR); and posterior rectilinear (PR). 
- Gradual anterior curve: the sternum has a gradual curve throughout its body, with its lower end in an anterior direction;

- Gradual vertical curve: the sternum has a gradual curve throughout its body, with its lower end in a vertical direction;

- Gradual posterior curve: the sternum is gradually curved throughout its body, with its lower end in a posterior direction;

- Proximal third curve: the sternum has an acute angulation in its proximal third only;

- Middle third curve: the sternum has an acute angulation in its middle third only;

- Distal third curve: the sternum has an acute angulation in its distal third only;

- Anterior rectilinear: the sternum is all rectilinear with its distal end in an anterior direction;

- Vertical rectilinear: the sternum is all rectilinear with its distal end in a vertical direction;

- Posterior rectilinear: the sternum is all rectilinear with its distal end in a posterior direction.

\section{Statistical analysis}

The SPSS software package version 15.0 (IBM Corp., Armonk, NY) was used for the statistical analysis and the comparisons of 1) each pectus type and the control group and 2) between each type of pectus. The Pearson's chi-squared test (cross-tabulation) was used to compare tomographic parameters among all groups. One-way analysis of variance (ANOVA) for independent groups was used to calculate the difference of means of radiographic parameters among the groups. A p-value less than or equal to 0.05 was considered statistically significant.

\section{RESULTS}

Table 2 shows the sternal body curvature patterns found in the control group and patients with different types of pectus.

Table 2. Types of sternum body curvatures in the control and pectus groups

\begin{tabular}{c|c|c|c|c|c|c}
\hline & $\begin{array}{c}\text { CONTROL } \\
\text { GROUP }\end{array}$ & SPC & IPC & LPC & LPE & BPE \\
\hline $\begin{array}{c}\text { Anterior } \\
\text { rectilinear }\end{array}$ & $13(26 \%)$ & $0(0 \%)$ & $\begin{array}{c}26 \\
(50 \%)\end{array}$ & $\begin{array}{c}7 \\
(29.1 \%)\end{array}$ & $4(7.7 \%)$ & $\begin{array}{c}5 \\
(19.2 \%)\end{array}$ \\
\hline $\begin{array}{c}\text { Gradual } \\
\text { vertical curve }\end{array}$ & $24(48 \%)$ & $\begin{array}{c}4 \\
(30.7 \%)\end{array}$ & $\begin{array}{c}11 \\
(21.1 \%)\end{array}$ & $\begin{array}{c}7 \\
(29.1 \%)\end{array}$ & $\begin{array}{c}8 \\
(15.4 \%)\end{array}$ & $0(0 \%)$ \\
\hline $\begin{array}{c}\text { Gradual } \\
\text { anterior curve }\end{array}$ & $4(8 \%)$ & $0(0 \%)$ & $\begin{array}{c}9 \\
(17.3 \%)\end{array}$ & $\begin{array}{c}4 \\
(16.7 \%)\end{array}$ & $1(1.9 \%)$ & $0(0 \%)$ \\
\hline $\begin{array}{c}\text { Vertical rectilinear } \\
\text { Distal third curve }\end{array}$ & $3(6 \%)$ & $\begin{array}{c}1 \\
(7.6 \%)\end{array}$ & $0(0 \%)$ & 0 & $0(0 \%)$ & $\begin{array}{c}3 \\
(11.5 \%)\end{array}$ \\
\hline $\begin{array}{c}\text { Gradual } \\
\text { posterior curve }\end{array}$ & $0(0 \%)$ & $\begin{array}{c}1 \\
(7.6 \%)\end{array}$ & $2(3.8 \%)$ & $\begin{array}{c}3 \\
(12.5 \%)\end{array}$ & $\begin{array}{c}32 \\
(61.5 \%)\end{array}$ & $\begin{array}{c}10 \\
(38.4 \%)\end{array}$ \\
\hline $\begin{array}{c}\text { Proximal } \\
\text { third curve }\end{array}$ & $1(2 \%)$ & $\begin{array}{c}4 \\
(30.7 \%)\end{array}$ & $2(3.8 \%)$ & 0 & $2(3.8 \%)$ & $1(3.8 \%)$ \\
\hline Middle third curve & $1(2 \%)$ & $\begin{array}{c}1 \\
(7.6 \%)\end{array}$ & $0(0 \%)$ & 0 & $1(1.9 \%)$ & $0(0 \%)$ \\
\hline $\begin{array}{c}\text { Posterior } \\
\text { rectilinear }\end{array}$ & $0(0 \%)$ & $0(0 \%)$ & $0(0 \%)$ & 0 & $0(0 \%)$ & $\begin{array}{c}3 \\
(11.5 \%)\end{array}$ \\
\hline TOTAL & 50 & 13 & 52 & 24 & 52 & 26 \\
\hline
\end{tabular}

IPC: inferior pectus carinatum; LPC: lateral pectus carinatum; SPC: superior pectus carinatum; LPE: localized pectus excavatum; BPE: broad pectus excavatum.

There was a high incidence of gradual vertical and anterior rectilinear curvature in the control group ( $p=.001)$ (Figure 3$)$.

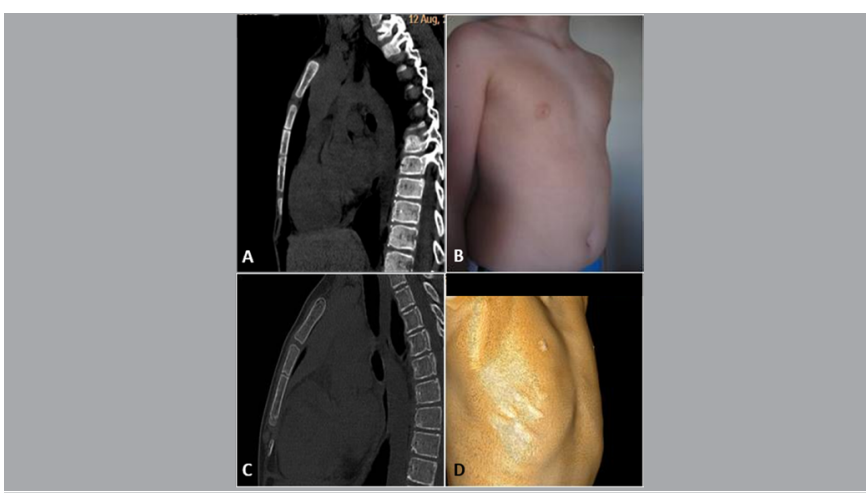

Figure 3. Examples of the most common sternal patterns in the control group: the vertical curved ( $\mathrm{A}$ and $\mathrm{B}$ ) and the anterior rectilinear types (C and D)

\section{Comparison between the control and pectus groups}

The following statistically significant findings were found when comparing sternal patterns between each pectus type and the controls $(n=50)$ :

a) SPC versus controls: Higher prevalence of proximal third and gradual posterior curves and a lower prevalence of anterior rectilinear in patients with SPC $(n=13)$ than in the controls $(n=50)(p=.03)$; b) IPC versus controls: Higher prevalence of the anterior rectilinear type and a lower prevalence of the gradual vertical curve and vertical rectilinear types in IPC $(n=52)$ than the controls $(p=.01)$; c) LPE versus controls: Patients with LPE $(n=52)$ had a lower prevalence of anterior rectilinear, gradual vertical, and vertical rectilinear types and higher prevalence of gradual posterior curve than the controls $(p=.00)$;

d) BPE versus controls: Patients with BPE $(n=26)$ presented a higher prevalence of gradual posterior and posterior rectilinear types and a lower prevalence of gradual vertical curve than the controls $(p=.00)$; and

e) There was no significant difference between the control group and patients with LPC $(n=24)(p>.05)$.

We clinically observed patients with the same type of pectus but with different sternal tomographic patterns (Figures 4 to 7 ).

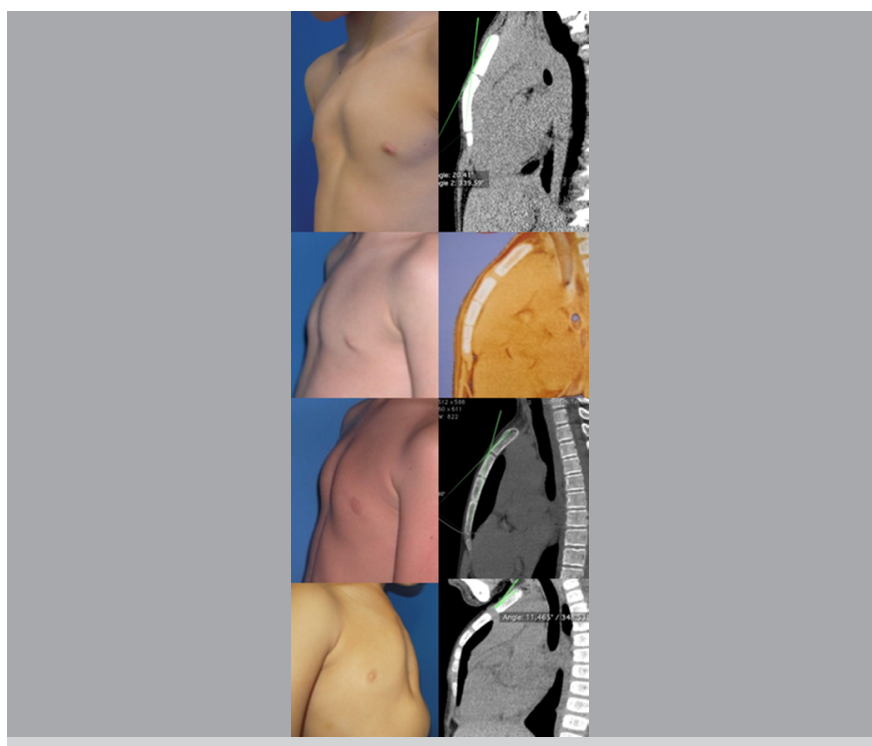

Figure 4. Patients with the same clinical type of pectus (SPC), but with different sternal patterns. Even the clinical types that were classified as SPC, representing cases in which the chest was more prominent than normal in its most proximal region, were not necessarily the same. 

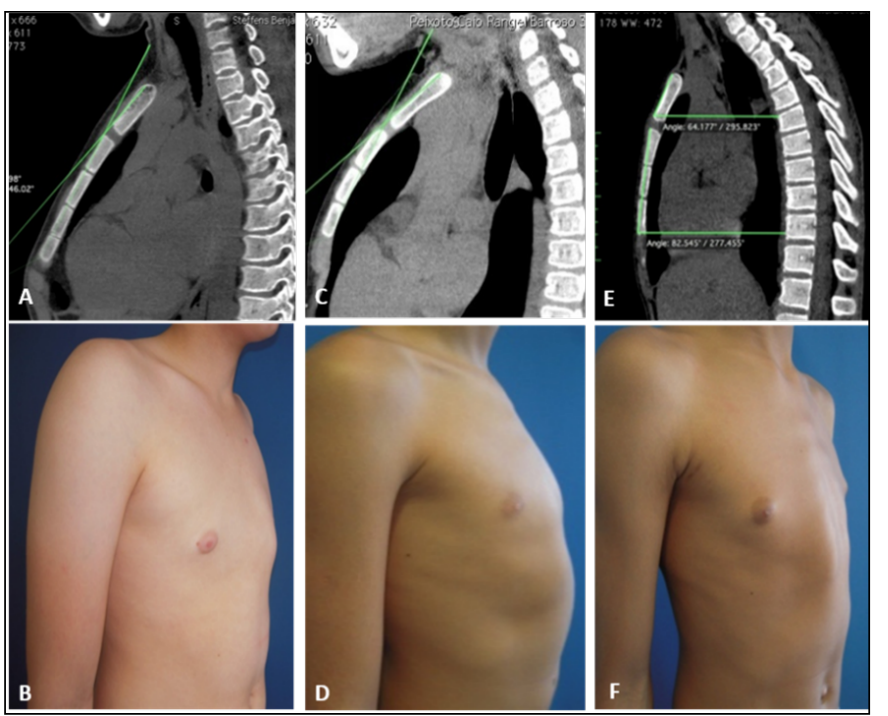

Figure 5. Patients with the same clinical type of pectus (IPC), but different sternal patterns. Although it was clear that the clinical type was IPC, we observed that the sternal patterns, anterior rectilinear, and gradual anterior curvature had the clinical apex of the deformity closer to the mammary line. In the gradual vertical curvature, this clinical apex seemed more distal and the whole sternal body seemed projected more anteriorly and not only its distal portion.

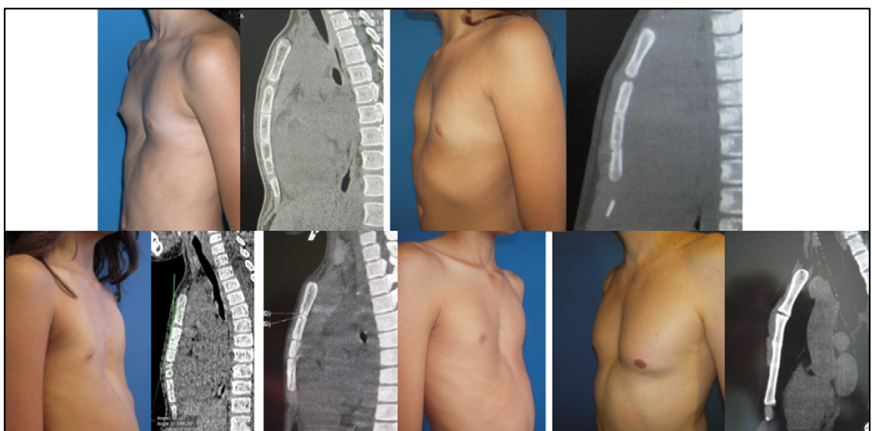

Figure 6. Patients with the same clinical type of pectus (LPE), but different sternal patterns. Note that even the clinical types classified as $\mathrm{LPE}$, representing cases in which the thorax presented a localized and central depression area, were not necessarily the same.

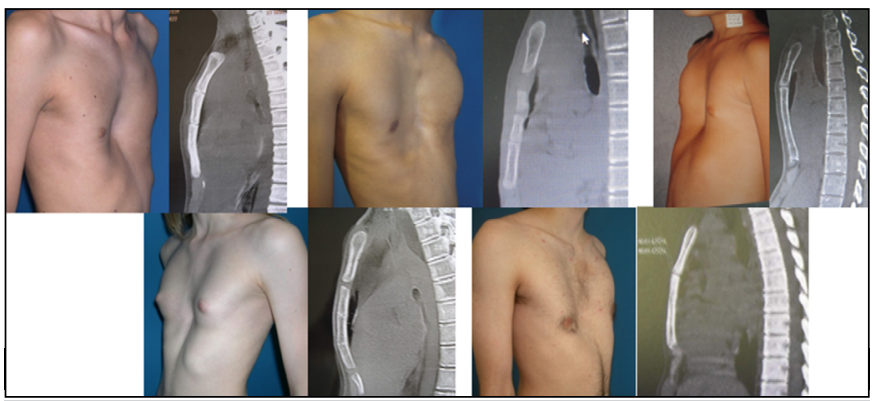

Figure 7. Patients with the same clinical type of pectus (BPE), but different sternal patterns. Note that even the clinical types classified as BPE, representing cases in which the chest presents a wide area of depression, were not necessarily the same.

\section{Analysis between different types of pectus}

The following statistically significant findings were found when comparing sternal patterns between each type of pectus: a) BPE versus LPE: Patients with LPE had a higher prevalence of gradual vertical and posterior curve and a lower incidence of vertical and posterior rectilinear than the patients with BPE $(p=.003)$;

b) $L=I P C$ versus $L P E$ : Patients with $L P C$ had a higher prevalence of anterior rectilinear and gradual anterior curve and lower prevalence of gradual posterior curved than the patients with LPE $(p=.00)$; c) SPC versus LPE: Patients with SPC had a higher prevalence of vertical rectilinear and proximal third and middle third curves, and lower prevalence of gradual posterior curve than the patients with $\operatorname{LPE}(\mathrm{p}=.00)$;

d) SPC versus BPE: Patients with SPC had a higher prevalence of gradual vertical curve and proximal third curve, and lower prevalence of gradual posterior curve than the patients with BPE $(p=.00)$;

e) SPC versus IPC: Patients with SPC had a higher prevalence of vertical rectilinear and distal and proximal third curve types, and lower prevalence of anterior rectilinear and gradual anterior curve than the patients with IPC $(p=.00)$;

f) SPC versus $L P C$ : Patients with SPC had a higher prevalence of proximal third curve types and a lower incidence of anterior rectilinear and gradual anterior curve than the patients with LPC $(p=.016)$; g) $L P C$ versus $L P E$ : Patients with LPC $(n=24)$ had a higher prevalence of anterior rectilinear and gradual anterior curve, and lower prevalence of gradual posterior curve than the patients with LPE $(\mathrm{n}=52)(\mathrm{p}=.00)$; and

h) There was no significant difference between the IPC and LPC groups of pectus regarding the type of sternal curvature $(p=.24)(p>.05)$. We observed patients with different clinical types of pectus but with very similar sternal patterns (Figure 8).

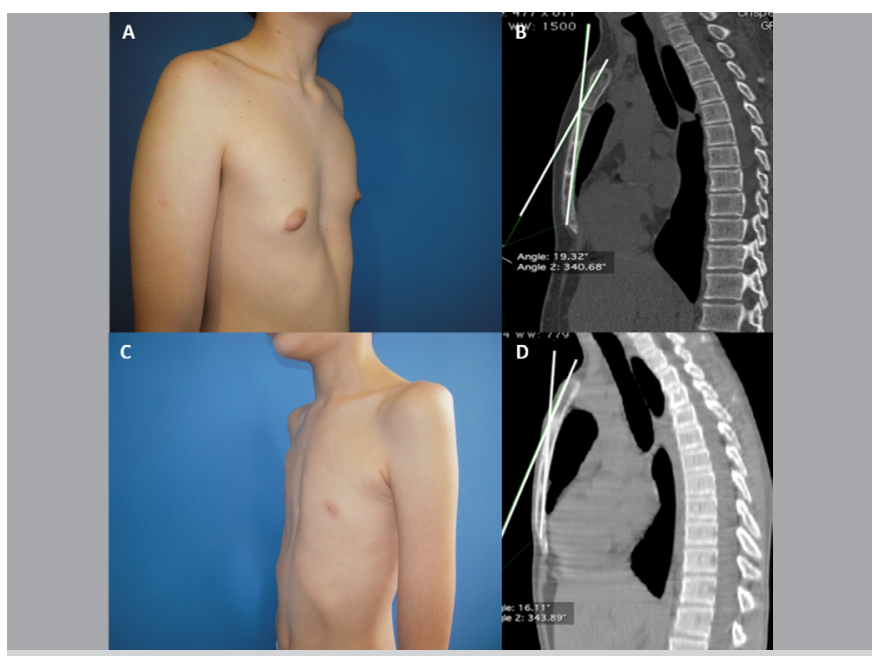

Figure 8. Patients with localized pectus excavatum (a) with gradual vertical curve sternal pattern (b) and another patient with lateral pectus carinatum (c) with the same sternal pattern (d).

\section{DISCUSSION}

This study created radiographic parameters that can eventually be described in reports on the thoracic region, as they help clarify the shape of the sternal bone in the sagittal plane in normal individuals and patients with pectus.

In the control group, the gradual posterior curve and posterior rectilinear types were not found, whereas the gradual vertical curve and anterior rectilinear types prevailed, which is an interesting and novel observation. A radiologist that did not previously clinically analyzed the patient, but analyzed an exam that has sternum of the gradual posterior curve and posterior rectilinear types, will know that the patient probably has pectus. It is not uncommon for radiologic exams of pectus patients with the description of "normal" or "no alterations". 
We also observed patients with different pectus deformities but with similar curvature patterns of the sternum in sagittal reconstruction, which is also novel. There were patients with the same type of pectus but with different types of sternal body curvatures. That is an important observation when analyzing the pectus etiopathogeneses. In some cases, growth abnormalities in the sternum region or sternum pattern curvature may not be related to pectus etiology or appearance, since some different clinical pectus have the same radiologic sternum pattern.

Except for the posterior rectilinear type that occurred only in BPE cases, the other types of sternal curvatures were not specific to patients with pectus. Some types were more frequent, whereas others were not found in certain pectus. In the cases of pectus excavatum, the gradual posterior curve sternum was more frequent than other types. Most patients in the IPC, and LPC group showed anterior rectilinear and gradual vertical curves. In the SPC group, the proximal third curve and gradual vertical curve together accounted for $61.4 \%$ (8 of 13 patients) of the cases, the former being rare.

Some consider the sternum as the key factor causing pectus, with its distal end being more depressed in cases of pectus excavatum, and the opposite in cases of pectus carinatum. ${ }^{6}$ However, our study showed that this does not always occur and that there are cases of anterior rectilinear, vertical rectilinear, gradual anterior curve, and gradual vertical curve types in pectus excavatum cases. We also observed cases of pectus carinatum with the distal end of the sternum inclined in the posterior direction.

The clinical types classified as SPC, LPE, and BPE were not necessarily the same, suggesting the need to improve the clinical classification of these pectus subtypes. Haje et al. ${ }^{5}$ recently subdivided the LPE and SPC classifications. Better defined clinical subtypes may help create or improve tomographic parameters to differentiate them.

Due to variation in the shape of the anterior thoracic wall in normal individuals, it may be difficult to clinically and radiologically define the limits between a mild case of pectus and a patient with a normally shaped anterior thoracic wall. Our extensive experience in treating these deformities with orthoses and exercises shows that there are patients with discrete pectus that wish to undergo treatment and patients with mild or moderate pectus that have always considered themselves as normal and have no intention of undergoing therapy. When Haller's index was previously evaluated, it was measured at the point of greatest sternal depression in the sternal region, being evaluated before and after pectus excavatum correction surgery. ${ }^{2}$ The present radiological parameters may also be used in the pre- and post-treatment evaluation of patients with pectus excavatum, especially in corrective surgeries with sternal body osteotomies, such as the surgical treatment of superior or Currarino pectus types (SPC). ${ }^{7}$ The knowledge of several sternal patterns in the sagittal analysis of the sternal region may help to better understand the etiopathogenesis of pectus deformities and plan the most adequate treatment in surgical cases and suggest appropriate classification criteria

Before the analysis, it was important to find the midline of the sternum, which is not necessarily the midline of the body. We also know that may be inclined or obliquus to the body when the sternum is seen in the coronal plane, thus complicating tracing the median line.

A present bias was that the analyzed parameters were subjected to intra- and inter-examiner interpretation variations. Further studies are necessary to verify the reliability of our method. Although we used a control group, it is unknown that tomographic parameters vary with age and sex in normal/control individuals.

Initially, in some situations, a CT scan of the anterior thoracic wall was requested by the authors to better understand these deformities. Recently, CT scans are no longer requested because tomographic and clinical patterns seemed to repeat themselves and this examination is not a determining factor for orthosis and exercise-based therapy; ${ }^{5,8}$ moreover, there are growing concerns regarding radiation by the examination. ${ }^{5}$ The examination can sometimes be used to evaluate prognosis in selected patients, especially in mild SPC in children to evaluate early fusion of the manubriosternal region or sternal shortening, and in some LPC cases in which the pectoral region is asymmetrical, and the degree of bone and soft tissue deformity (breast and/or muscle involvement). Most of the cases in our study were detected before 2009. The cases after that year included CT examinations requested by other colleagues before referral to our pectus treatment center.

\section{CONCLUSION}

In conclusion, the suggested classification of sternal curvature types provided initial radiological parameters in patients with pectus and controls and evidence of differentiation between them.

AUTHORS' CONTRIBUTIONS: Each author contributed individually and significantly to the development of this article. DPH: conception and design of the study, acquisition of data, analysis and interpretation of data, drafting the article, revising it critically for important intellectual content, final approval of the version to be published; KOT: conception and design of the study, acquisition of data, analysis and interpretation of data and final approval of the version to be published; MSN: conception and design of the study, acquisition of data, analysis and interpretation of data, drafting the article, revising it critically for important intellectual content, final approval of the version to be published; JBV: conception and design of the study, acquisition of data, analysis and interpretation of data, drafting the article, revising it critically for important intellectual content, final approval of the version to be published; PSM: conception and design of the study, acquisition of data, analysis and interpretation of data, drafting the article, revising it critically for important intellectual content, final approval of the version to be published; PD: drafting the article, revising it critically for important intellectual content, final approval of the version to be published.

\section{REFERENCES}

1. Haje SA, Haje DP, Silva Neto M, Cassia GS, Batista RC, Oliveira GRA, Mundim TL. Pectus deformities: tomographic analysis and clinical correlation. Skeletal Radiol. 2010;39(8):773-82.

2. Haller JA Jr, Kramer SS, Lietman SA. Use of CT scans in selection of patients for pectus excavatum surgery: a preliminary report. J Pediatr Surg. 1987;22(10):904-6.

3. Haje SA, Harcke HT, Bowen JR. Growth disturbance of the sternum and pectus deformities: imaging studies and clinical correlation. Pediatr Radiol. 1999;29(5):334-41.

4. Bayaroğulları H, Yengil E, Davran R, Ağlagül E, Karazincir S, Balcı A. Evaluation of the postnatal development of the sternum and sternal variations using multidetector CT. Diagn Interv Radiol. 2014;20(1):82-9.
5. Haje S, Haje DP, Silva Neto M. Tórax e cintura escapular. In: Hebert SK, Barros Filho TEP, Xavier R, Pardini AG Jr, editores. Ortopedia e traumatologia: princípios e prática. 5th ed. Porto Alegre: Artmed Editora; 2017. p. 81-100.

6. Robicsek F, Daugherty HK, Mullen DC, Harbold NB Jr, Jackson RD, et al. Technical considerations in the surgical management of pectus excavatum and carinatum. Ann Thorac Surg. 1974;18(6):549-64.

7. Kuzmichev V, Ershova K, Adamyan R. Surgical correction of pectus arcuatum. J Vis Surg. 2016;2:55.

8. Haje SA, Bowen JR. Preliminary results of orthotic treatment of pectus deformities in children and adolescents. J Pediatr Orthop. 1992;12(6):795-800. 